Mark E. Hudson MD, Kenneth P. Rothfield MD, William C. Tullock MD, Leonard L. Firestone MD

\title{
Haemodynamic effects of rocuronium bromide in adult cardiac surgical patients
}

Purpose: To measure the haemodynamic effects of rocuronium in adults undergoing cardiac surgery with cardiopulmonary bypass (CPB).

Methods: Twenty patients undergoing elective cardiac surgical procedures with moderate hypothermic nonpulsatile bypass participated in this prospective, observational study. After anaesthetic induction, recovery from succinylcholine, and achievement of baseline haemodynamic stability, patients received $0.6 \mathrm{mg} \mathrm{kg}^{-1}$ rocuronium as an initial rapid intravenous bolus. Maintenance dosing of $0.2 \mathrm{mg} \cdot \mathrm{kg}^{-1}$ was continued for the remainder of the procedure. Haemodynamic measurements (heart rate, systemic arterial systolic, diastolic, and mean arterial pressure, pulmonary arterial systolic, diastolic, and mean pressure, pulmonary capillary wedge pressure, central venous pressure, and thermodilution cardiac output measurements) were obtained for the first five minutes after rocuronium administration, and subjects were observed for histamine-related symptoms.

Results: Central venous pressure decreased from baseline at two and five minutes after the rocuronium bolus, and mean pulmonary artery pressure decreased at five minutes. No changes were observed in heart rate, mean systemic arterial pressure, pulmonary capillary wedge pressure, cardiac index, stroke volume, systemic vascular resistance, or pulmonary vascular resistance, nor did any patient manifest any other histamine-related symptoms. Conclusion: The haemodynamic profile for a $0.6 \mathrm{mg} \cdot \mathrm{kg}^{-1}$ bolus of rocuronium is acceptable for patients with cardiovascular disease.

Objectif : Mesurer les effets hémodynamiques du rocuronium chez des adultes subissant une chirurgie cardiaque sous CEC.

Méthodes : Vingt patients subissant une chirurgie cardiaque sous CEC à flot non pulsatile et sous hypothermie modérée ont participé à cette étude d'observation prospective. Après l'induction de l'anesthésie, récupération de l'effet de la succinylcholine et obtention d'une stabilité hémodynamique de base, les patients ont reçu par voie IV rapide un bolus initial de $0,6 \mathrm{mg} \cdot \mathrm{kg}^{-1}$ de rocuronium suivi de doses de maintien de $0,2 \mathrm{mg} \cdot \mathrm{kg}^{-1}$ durant toute la durée de la procédure. Durant les premières cinq minutes aprés l'administration de rocuronium, les mesures hémodynamiques suivantes ont été obtenues : rythme cardiaque, pression artérielle systémique et pulmonaire, systolique, diastolique et moyenne, pression capillaire bloquée, pression veineuse centrale et mesures du débit cardiaque par thermodilution. On a aussi recherché chez les patients de symptômes liés à la libération d'histamine.

Résultats : Après un bolus de rocuronium, on a observé une diminution de la pression veineuse centrale après deux et cinq minutes. Les autres variables, rythme cardiaque, pression artérielle moyenne, pression capillaire bloquée, index cardiaque, volume d'éjection, résistance vasculaire pulmonaire et systémique, n'ont présenté aucun changement. Aucun patient n'a démontré de symptômes liés à la libération d'histamine.

Conclusion : Une dose bolus de $0,6 \mathrm{mg} \cdot \mathrm{kg}^{-1}$ de rocuronium possède un profil hémodynamique acceptable pour des patients présentant maladie cardiovasculaire.

From the Cardiac Anaesthesia Service and Clinical Trials Program, Department of Anesthesiology and Critical Care Medicine, University of Pittsburgh, Pittsburgh, Pennsylvania.

Address correspondence to: Mark E. Hudson MD, Department of Anesthcsiology, University of Pittsburgh Medical Center, 200 Lothrop Street, Pitrsburgh, PA 15213; Phonc: 412-647-6733; Fax: 412-647-6290.

This work was supported by a grant (to LLF) from Organon Inc.

Accepted for publication November 29, 1997. 
$\mathrm{R}$

OCURONIUM bromide is a nondepolarising steroidal neuromuscular blocking agent with a rapid onset ${ }^{1,2}$ and minimal cardiovascular side effects in animal studies. ${ }^{3,4}$ It thus might be useful for emergency anaesthetic inductions, particularly when rapid intubation must be performed in patients with cardiovascular disease. However, the haemodynamic effects of rocuronium in humans remain incompletely characterised, and published data are inconsistent. With bolus administration, some previous studies documented an increase in heart rate (HR), ${ }^{5}$ pulmonary vascular resistance (PVR), ${ }^{6}$ stroke volume index (SVI) and cardiac index (CI), with decreased pulmonary capillary wedge pressure (PCWP), ${ }^{7}$ whereas other studies found no haemodynamic changes. ${ }^{8,9}$ Thus, the goal of this study was to clarify the haemodynamic responses to bolus administration of rocuronium in adult cardiac surgical patients.

\section{Methods}

With University of Pittsburgh Biomedical Institutional Review Board approval and signed written informed consent, 20 ASA class 3 or 4 patients undergoing elective cardiac surgical procedures (17 coronary artery bypass graft procedures, two mitral valve replacements, and one aortic valve replacement) with moderate hypothermia (mean low temperature $31.3^{\circ} \mathrm{C}$, range $30-34^{\circ} \mathrm{C}$ ) nonpulsatile bypass were enrolled (11 men and nine women; mean age of 65.2 years, range $27-80$ years). Exclusion criteria included airway abnormality or obstruction; pregnancy; clinically significant renal, hepatic, or neuromuscular disorders; inadequately controlled systemic hypertension; morbid obesity; allergy to opioids or other anaesthetic agents; treatment with an antihistamine; severe metabolic disorder other than diabetes mellitus; or treatment with an anticonvulsant or aminoglycoside or polypeptide antibiotic in doses that could affect the action of neuromuscular blocking drugs.

All chronic cardiac medications were continued through the morning of surgery. Subjects received a standard premedication of morphine sulfate (up to $0.15 \mathrm{ml} \cdot \mathrm{kg}^{-1}$ ) and either scopolamine (up to $0.4 \mathrm{mg}$ $i m$ ) or a benzodiazepine (i.e., lorazepam, $2-4 \mathrm{mg}$ ) 60 to $90 \mathrm{~min}$ before the induction of anaesthesia. On arrival at the operating room, HR, heart rhythm, systemic oxygen saturation, and blood pressure were monitored. Peripheral venous and arterial cannulas, as well as a multilumen pulmonary artery catheter, were inserted under local anaesthesia in all patients.

Anaesthesia was induced with $25-50 \mu \mathrm{g} \cdot \mathrm{kg}^{-1}$ fentanyl with oxygen $100 \%$. Succinylcholine (1.0-1.5 $\mathrm{mg}^{\mathrm{kg}}{ }^{-1}$, up to a total of $120 \mathrm{mg}$ ) was administered to facilitate tracheal intubation. Anaesthesia was maintained with incremental doses of fentanyl (up to a maximum total dose of $100 \mu \mathrm{g} \cdot \mathrm{kg}^{-1}$ ) with oxygen $100 \%$. Heart rate and systolic and diastolic blood pressure were recorded before induction, just before the administration of succinylcholine, and at 2, 5, 10, and $15 \mathrm{~min}$ after succinylcholine to document haemodynamic stability. Subjects demonstrating haemodynamic instability (defined as a $20 \%$ change from baseline for systemic arterial pressure and HR) were excluded from the study. At a minimum of $15 \mathrm{~min}$ following the succinylcholine bolus and with neuromuscular recovery confirmed (as determined by the return of the train-of-four [TOF] with peripheral nerve stimulation, Neurotechnology Digi Stim III, Neurotechnology, Houston, Texas), baseline recordings of $\mathrm{HR}$, systemic arterial systolic and diastolic pressure, mean arterial pressure (MAP), pulmonary arterial systolic, diastolic, and mean blood pressure, PCWP, central venous pressure (CVP), and thermodilution cardiac output measurements were obtained. CI, stroke volume (SV), systemic vascular resistance (SVR), PVR, and left ventricular stroke work index (LVSWI) were derived later from these measured haemodynamic values using standard formulas. ${ }^{10}$

After acquisition of baseline data, $0.6 \mathrm{mg} \cdot \mathrm{kg}^{-1}$ rocuronium was injected over five seconds into a fastflowing peripheral intravenous catheter. Heart rate, systolic and diastolic pressures, and MAP were recorded every minute for the first five minutes after injection. In addition to these variables, pulmonary arterial systolic and diastolic, and mean blood pressure, PCWP, CVP, and thermodilution cardiac output measurements were obtained at two and five minutes after injection. The CI, SV, SVR, PVR, and LVSWI were later derived, as above. Subjects were observed at all time points for histamine-related signs or symptoms, including tachycardia, hypotension, or skin flushing. No patient received further fentanyl bolus after documentation of haemodynamic stability following succinylcholine bolus until completion of dara collection five minutes after rocuronium bolus.

A clinically significant alteration in haemodynamic variables was defined, before the start of data collection, as a $20 \%$ change from baseline. The haemodynamic data were compared among time points using repeatedmeasures analysis of variance followed by paired $t$ tests. For all tests, $\alpha$ was set at 0.05 , and a Bonferroni adjustment was used for multiple pairwise comparisons.

\section{Results}

The CVP decreased $(P<0.01)$ at two and five minutes after rocuronium administration, and mean pulmonary artery pressure (MPAP) decreased at five minutes $(P=0.02)$ (refer to the Table on the following page). 
TABLE Haemodynamic responses to rocuronium administration

\begin{tabular}{|c|c|c|c|}
\hline & $0 \mathrm{~min}$ & $2 \mathrm{~min}$ & $5 \mathrm{~min}$ \\
\hline HR (bpm) & $67.7 \pm 3.3$ & $69.9 \pm 3.5$ & $68.5 \pm 3.4$ \\
\hline $\mathrm{MAP}(\mathrm{mmHg})$ & $86.5 \pm 3.2$ & $86.5 \pm 2.8$ & $86.7 \pm 3.3$ \\
\hline CVP (mmHg) & $10.6 \pm 1.1$ & $8.8 \pm 0.9^{*}$ & $8.5 \pm 0.9^{*}$ \\
\hline PCWP (mmHg) & $13.0 \pm 1.2$ & $12.3 \pm 1.3$ & $12.4 \pm 1.3$ \\
\hline MPAP (mmHg) & $22.3 \pm 1.1$ & $21.4 \pm 1.2$ & $20.5 \pm 1.0^{\dagger}$ \\
\hline $\mathrm{CI}\left(1 \cdot \mathrm{min}^{-1} \cdot \mathrm{m}^{-2}\right)$ & $2.37+0.12$ & $2.32 \pm 0.15$ & $2.34+0.14$ \\
\hline $\mathrm{SV}\left(\mathrm{ml}\right.$-beat $\left.{ }^{-1}\right)$ & $66.2 \pm 3.0$ & $63.0 \pm 3.9$ & $64.4 \pm 3.2$ \\
\hline SVR (dyn $\sec \cdot \mathrm{cm}^{-5}$ ) & $1427.1 \pm 74.5$ & $1518.3 \pm 82.2$ & $1520.5 \pm 92.6$ \\
\hline PVR (dyn $\left.\cdot \mathrm{sec} \cdot \mathrm{cm}^{-5}\right)$ & $164.8 \pm 11.5$ & $168.0 \pm 12.5$ & $154.3 \pm 11.9$ \\
\hline LVSWI $\left(\mathrm{g} \cdot \mathrm{m}^{-1} \cdot \mathrm{m}^{-2}\right)$ & $35.8 \pm 2.6$ & $33.9 \pm 2.3$ & $34.5 \pm 2.1$ \\
\hline
\end{tabular}

Note: Control ( 0 time, immediately before injection) and responses at two minutes and five minutes following injection are listed. Values are mean $\pm S E M ;(n=20)$. HR = heart rate;

$\mathrm{MAP}=$ mean arterial pressure; $\mathrm{CVP}=$ central venous pressure;

PCWP = pulmonary capillary wedge pressure;

MPAP = mean pulmonary artery pressure; $\mathrm{Cl}=$ cardjac index;

$\mathrm{SV}=$ stroke volume; SVR = systemic vascular resistance;

PVR = pulmonary vascular resistance;

LVSWI $=$ left ventricular stroke work index.

$* P<0.01+P=0.02$

The changes in CVP met the pre-established criteria for

"clinical" significance in eight of the 20 study patients (Figure 1). In contrast, although MPAP also decreased on average in the study group, three of the patients developed clinically significant (i.e., $>20 \%$ ) increases in MPAP two minutes after rocuronium administration (Figure 1). None of the three patients demonstrated any increase in systolic pulmonary artery pressure. The increase in MPAP was due to an increase in diastolic pulmonary artery pressure. No other change, either in groups or individuals, occurred in the other measured or calculated haemodynamic variables, nor did any patient demonstrate any histamine-related symptoms.

\section{Discussion}

Haemodynamic stability is vital to successful anaesthetic management of myocardial revascularisation procedures or valve repair or replacement. Patients undergoing these procedures may have very limited cardiovascular reserve, and any increase in myocardial oxygen demand from increased $H R$, wall tension, or contractility, or a decrease in coronary perfusion from hypotension may result in ischemia. Therefore, the choice of anaesthetic adjuvants, such as neuromuscular blocking agents, must be based on maintaining optimal haemodynamics. Cardiac parients undergoing emergency procedures, or those requiring rapid control of the airway, pose particular difficulty. In such patients, succinylcholine cannot be used routinely, because of the potential for arrhythmias or bradycardia. ${ }^{11}$ Vecuronium has a relatively slow onset and has been associated with
A. Percent Change in CVP and MPAP 2 min

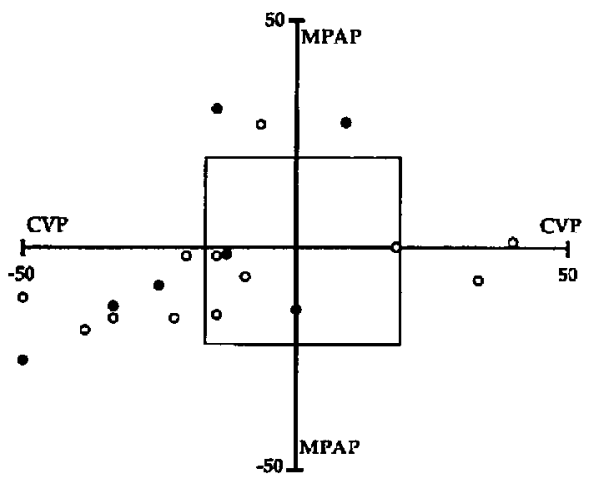

B. Percent Change in CVP and MPAP 5 min

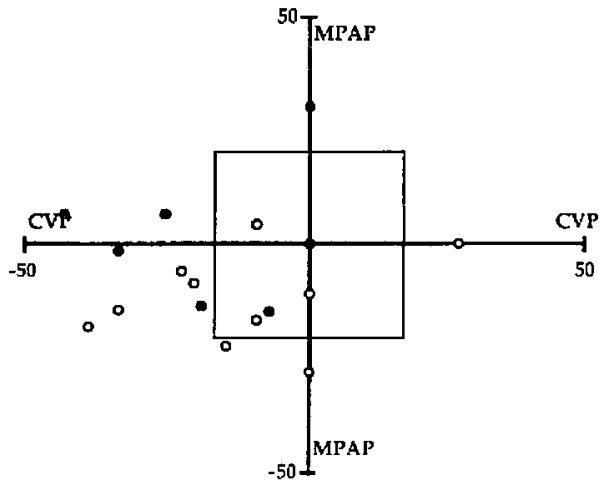

FIGURE 1 The percentage change in mean pulmonary artery pressure (MPAP) versus percentage change in central venous pressure (CVP) at two minutes (A) and five minutes (B) after bolus injection of rocuronium. The central box represents a $20 \%$ change from baseline, which was defined as a clinically significant change.

The open circles represent subjects chronically medicated with beta-blockers and/or calcium channel blockers.

bradycardia when used with high-dose fentanyl. ${ }^{12,13}$ Pipecuronium and doxacurium have more favourable hacmodynamic profiles but are slower in onset and longer in duration. ${ }^{14,15}$ Therefore, a muscle relaxant that facilitates rapid intubation without compromising haemodynamic stability would be highly useful. We undertook this study to evaluate whether rocuronium had such properties. We found that rocuronium pro- 
duced haemodynamic changes consistent with mild systemic venodilatation, which is acceptable for patients with limited cardiac reserve.

Although animal studies revealed few undesirable haemodynamic effects of rocuronium boluses, evidence for its potential to increase HR has been observed. For example, when compared with vecuronium, rocuronium manifests less vagal blocking action at similar levels of neuromuscular blockade. ${ }^{3}$ However, tachycardia was observed only at doses approaching five times the relaxation $\mathrm{ED}_{\mathbf{9 0}}$ in dogs. ${ }^{4}$ Initial studies in humans have also suggested an association between rocuronium and tachycardia. Booth et al. reported a $36 \%$ increase in $\mathrm{HR}$ with rocuronium in $\mathbf{3 0}$ healthy adults during halothane anaesthesia. ${ }^{5}$ Tachycardia of this magnitude is unacceptable in ischaemic heart disease patients but is not entirely consistent with findings from other studies cvaluating rocuronium. For example, in patients undergoing elective coronary artery bypass grafting under fentanyl anaesthesia, $\mathrm{McCl}$ et al. found only mild ( $7 \%$ ) increases in HR and perhaps a mild inotropic effect, as suggested by an increased SVI.? Numerous factors including anaesthetic regimen, premedication, chronic cardiac medications, patient population, or surgical stimulation may account for these observed differences.

Other unpublished observations, acknowledged in the manufacturer's package insert for rocuronium bromide (Zemuron ${ }^{\mathrm{TM}}$ ), indicate that increased PVR may be observed after administration of rocuronium. ${ }^{6}$ In contrast, Cornet $t$ t al. showed no change in $H R$, MAP, PCWP, or CI and no ischacmic cpisodes as evaluated by computerised ST-segment analysis and TEE evaluation of left ventricular function in patients maintained with rocuronium undergoing abdominal aortic surgery. ${ }^{8}$ These findings were similar to the findings of Levy et al., which showed no alteration in $\mathrm{HR}$, BP, MAP, or ECG after rocuronium in adult paticnts during nitrous oxide/oxygen-sufentanil Anaesthesia. ${ }^{9}$

Decreases in CVP and MPAP were observed in the present study, suggesting that rocuronium has systemic venodilatory effects. The PVR was not augmented, and no other haemodynamic change was noted in the grouped data. However, three individuals demonstrated a clinically significant increase in MPAP two minutes after injection of rocuronium (Figure 1), although this was due to increases in diastolic pulmonary artery pressure. This increase in diastolic pulmonary artery pressure suggests an increase in compliance in the pulmonary arterial systems of these patients. Contrary to the reports of both Booth et al. ${ }^{5}$ and McCoy et al., ${ }^{7}$ we observed no changes in HR (Figure 2). McCoy at al. did note changes similar, if statistically insignificant, to ours in $\mathrm{CVP}$ and MPAP; both decreased by $18 \%$ at five min-

\section{A. Percent Change in HR and MAP 2 min}

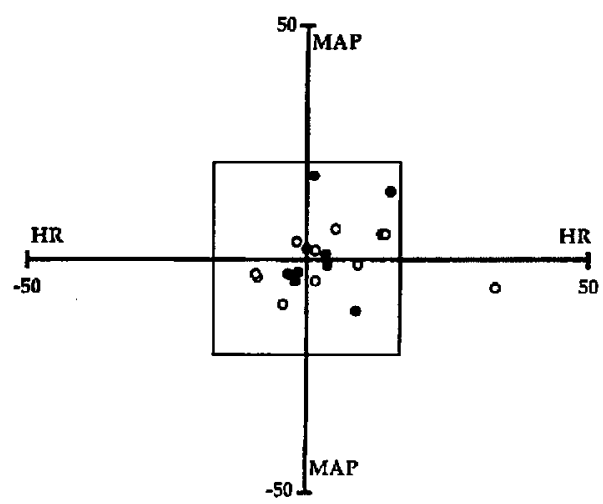

B. Percent Change in HR and MAP 5 min

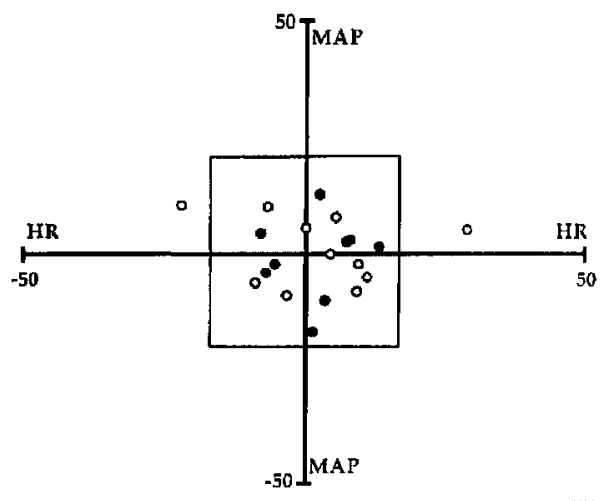

FIGURE 2 The percentage change in mean arterial pressure (MAP) versus percentage change in heart rate (HR) at two minutes (A) and five minutes (B) after bolus injection of rocuronium.

The central box represents a $20 \%$ change from baseline, which was defined as a clinically significant change. The open circles represent subjects chronically medicated with beta-blockers and/or calcium channel blockers.

utes. ${ }^{7}$ However, the small sample size probably accounts for the lack of statistical significance in these observations. As did Levy et al., ${ }^{9}$ we observed an absence of histamine-related symptoms. Eleven of the 20 study subjects were receiving beta-blockers and/or calcium channel blockers before surgery. No difference was observed between these subjects and other study subjects in haemodynamic response to rocuronium. 
Thus, we found the haemodynamic profile for a $0.6 \mathrm{mg} \cdot \mathrm{kg}^{-1}$ bolus of rocuronium to be acceptable for patients with coronary artery disease; no change occurred that would promote increases in myocardial oxygen demand or further decreases in oxygen supply. Although CVP and MPAP decreased significantly, rocuronium had no effect on PCWP, SVR, MAP, or CI.

Overall, these results indicate that clinical doses of rocuronium are not associated with haemodynamic instability in ASA class 3 and 4 patients undergoing cardiac surgery. Further study of patients with higher initial MPAP, such as those undergoing cardiac valvular surgery, may clarify the pulmonary vascular effects of rocuronium in particular subgroups of cardiac parients.

\section{Acknowledgments}

We would like to thank Raymond Policare RRT MPH, for expert help in data acquisition and processing; Lisa Cohn for help with statistical analysis and editorial advice; Francie Siegfried and Lisa Goetz for editorial assistance; Maggie Soncini for administrative support through our Clinical Trials Program; our cardiac anesthesiology and surgery colleagues at the University of Pittsburgh Medical Center; and Rich Sharer, Maria Aikens, and Fred Colosimo from Organon, Inc.

\section{References}

I Weirda JMKH, de Wit APM, Kuizenga K, Agoston S. Clinical observations on the neuromuscular blocking action of ORG 9426, a new steroidal non-depolarizing agent. Br J Anaesth 1990; 64: 521-3.

2 Bartkowski RR, Witkowski TA, Azad S, Lessin J, Marr $A$. Rocuronium onset of action: a comparison with atracurium and vecuronium. Anesth Analg 1993; 77 : 574-8.

3 Muir AW, Houston J, Green KL, Marshall RJ, Bowman WC, Marshall IG. Effects of a new neuromuscular blocking agent (ORG 9426) in anaesthetized cats and pigs and in isolated nerve-muscle preparations. Br J Anaesth 1989; 63: 400-10.

4 Cason B, Baker DG, Hickey RF, Miller RD, Agostan $S$. Cardiovascular and neuromuscular effects of three steroidal neuromuscular blocking drugs in dogs (ORG 9616, ORG 9426, ORG 9991). Anesth Analg 1990; 70: 382-8.

5 Booth MG, Marsh B, Bryden FMM, Robertson EN, Baird WLM. A comparison of the pharmacodynamics of rocuronium and vecuronium during halothane anaesthesia. Anaesthesia 1992; 47: 832-4.

6 Package insert for $\mathrm{Zemuron}^{\mathrm{TM}}$ (rocuronium bromide) injection. Organon Inc., West Orange, New Jersey, 1994.

7 McCoy EP, Maddineni VR, Elliott P, Mirakbur RK, Carson IW, Cooper RA. Haemodynamic effects of rocuronium during fentanyl anaesthesia: comparison with vecuronium. Can J Anaesth 1993; 40: 703-8.

8 Cornet JP, Abiad $M$, Coriat $P$, Saada $M$, Gosgnach $M L$, Viars $P$. Evaluation of the effects of rocuronium bromide on haemodynamics and left ventricular function in patients undergoing abdominal aortic surgery. Eur J Anaesthesiol 1994; 11(Suppl 9): 78-81.

9 Levy JH, Davis GK, Duggan J, Szlam F. Determination of the hemodynamics and histamine release of rocuronium (Org 9426) when administered in increased doses under $\mathrm{N}_{2} \mathrm{O} / \mathrm{O}_{2}$-sufentanil anesthesia. Anesth Analg 1994; 78: 318-21.

10 Reich $D L$, Kaplan JA. Hemodynamic monitoring. In: Kaplan JA (Ed.). Cardiac Anaesthesia, 3rd ed. Philadelphia: WB Saunders, 1993: 286.

11 Scott RPF, Belmont MR, Savarese JJ. Muscle relaxants and the cardiovascular system. In: Kaplan JA (Ed.). Cardiac Anaesthesia, 3rd ed. Philadelphia: WB Saunders, 1993: 535-56.

12 Salmemperä $M$, Peltola $K$, Takkunen $O$, Heinonen J. Cardiovascular effects of pancuronium and vecuronium during high-dose fentanyl anesthesia. Anesth Analg 1983 ; 62: 1059-64.

13 Milligan KR, Beers $H T$. Vecuronium-associated cardiac arrest (Letrer). Anaesthesia 1985; 40: 385.

14 Stanley JC, Carson IW, Gibson FM, et al. Comparison of the haemodynamic effects of pipecuronium and pancuronium during fentanyl anaesthesia. Acta Anaesthesiol Scand 1991; 35: 262-6.

15 Emmot RS, Bracey BJ, Goldhill DR, Yate PM, Flynn PJ. Cardiovascular effects of doxacurium, pancuronium and vecuronium in anaesthetized patients presenting for coronary artery bypass surgery. $\mathrm{Br}$ J Anaesth 1990; 65: 480-6. 